\title{
Characterization of Colletotrichum graminicola Isolates Resistant to Strobilurin-Related QoI Fungicides
}

\author{
Cruz Avila-Adame, Department of Plant Pathology, Cornell University, New York State Agricultural Experiment \\ Station, Geneva 14456; Gilberto Olaya, Syngenta Crop Protection, Inc., Vero Beach, FL 32967; and Wolfram \\ Köller, Department of Plant Pathology, Cornell University, New York State Agricultural Experiment Station
}

\begin{abstract}
Avila-Adame, C., Olaya, G., and Köller, W. 2003. Characterization of Colletotrichum graminicola isolates resistant to strobilurin-related QoI fungicides. Plant Dis. 87:1426-1432.

Isolates of Colletotrichum graminicola were collected from annual bluegrass or bent grass turf in Japan and the United States, and their sensitivities to QoI fungicides (QoIs) as well as their cytochrome $b$ sequences were characterized. Five isolates sampled from turf treated repeatedly with azoxystrobin were highly QoI resistant under both in vivo and in vitro test conditions. The nucleotide sequences of a large cytochrome $b$ gene segment involving the binding site of QoIs were fully homologous for all resistant isolates and contained the G143A target site mutation known to confer QoI resistance in other pathogens. QoI-sensitive isolates collected prior to treatments with QoIs were more diverse with regard to their cytochrome $b$ gene sequences and their phenotype responses to QoIs. All wild-type isolates retained a glycine in position 143 of cytochrome $b$. Three of the four QoI-sensitive isolates were, in addition, distinguished by leucines in positions 95,130 , and 141 , which were exchanged to threonine in all resistant but also in one of the sensitive isolates. In addition to a more pronounced divergence of cytochrome $b$ sequences, the sensitive wild-type isolates also were diverse with regard to the induction of alternative respiration in response to QoI action, as indicated by comparisons of QoI sensitivities displayed in the absence or presence of the alternative oxidase inhibitor salicylhydroxamic acid. These different phenotype responses expressed under in vitro test conditions had no or only a slight impact on anthracnose control in protective applications of azoxystrobin. Isolate responses in vitro were very similar for trifloxystrobin, indicating cross-resistance among the class of QoIs. Our results imply that $C$. graminicola falls into the class of pathogens with a potential for rapid selection of highly QoI-resistant phenotypes. Frequent monitoring of population sensitivities will be required to determine the status of population responses toward practical QoI resistance.
\end{abstract}

Colletotrichum graminicola (Ces.) G.W. Wils. infects a broad range of grasses, including annual bluegrass (Poa annua) and bent grasses (Agrostis spp.) of turf (43). As documented in recent studies, $C$. graminicola isolates display a high degree of host specificity $(7,9,20)$. The pathogen causes foliar and basal stem rot anthracnose, a disease responsible for severe thinning of turf and routinely managed with fungicides (43).

Strobilurin-related QoI fungicides such as azoxystrobin and trifloxystrobin have been introduced for the control of several turf diseases, including anthracnose $(1,16)$. Respective fungicides inhibit respiration by binding to the Qo center of cytochrome $b$, functioning as a crucial component of

Corresponding author: W. Köller

E-mail: WK11@cornell.edu

Current address of C. Avila-Adame: Department of Plant Pathology, North Carolina State University, Raleigh 27695.

Accepted for publication 6 July 2003.

Publication no. D-2003-0922-02R

(C) 2003 The American Phytopathological Society the mitochondrial complex III $(8,37,44)$. Two mechanisms of resistance to Qo inhibitors (QoIs) have been characterized in detail. Numerous fungal organisms can respond to QoI action by the expression of alternative respiration, a pathway circumventing electron transport through the cytochrome $b$ target site of QoIs $(3,23,26)$. The induction of this alternative pathway of respiration can serve as a highly effective rescue mechanism when pathogen sensitivities are tested in the absence of a host, but disease control is not impaired when host surfaces are protected by a QoI fungicide prior to infection $(5,32-34,46)$. Thus far, alternative respiration has not been directly affiliated with the occasionally rapid selection of QoI-resistant subpopulations of pathogens. Instead, mutational changes of the cytochrome $b$ target site are responsible for several cases of practical resistance to QoI fungicides $(8,18,19)$.

Target site mutations of cytochrome $b$ conferring resistance to QoIs have been described for Saccharomyces cerevisiae and some other organisms prior to the commercial introduction of QoI fungicides $(11,18,26,45)$. For laboratory mutants of Venturia inaequalis and, more recently,
Magnaporthe grisea, a G143A amino acid exchange in cytochrome $b$ was found to render a high level of QoI resistance $(4,6,14,45)$. Although this particular mutation had not been reported for resistant $S$. cerevisiae mutants, it has been affiliated with the emergence of practical QoI resistance $(8,18,19)$. Full documentation of G143A target site-resistant field isolates has been provided for powdery mildew of wheat $(10,15,36,40)$ and cucumber (21), for downy mildew of cucumber (21) and grapevine (42), and for black sigatoka of banana (39). The same mechanism has been reported for $M$. grisea (14), V. inaequalis $(8,18)$, and Dydimella bryoniae (8).

A different F129L cytochrome $b$ mutation conferring QoI resistance was identified in field isolates of $M$. grisea (14), Pythium aphanidermatum (31), and Alternaria solani (35). This F129L mutation had been reported for $S$. cerevisiae, where it rendered a high level of resistance to the natural QoI myxothiazole but a lower degree of resistance to the strobilurin-related QoIs tested $(22,26)$.

In the present study, responses to QoIs are characterized for baseline isolates of $C$. graminicola collected prior to the exposure of turf to QoI fungicides and for isolates collected from turf repeatedly treated with azoxystrobin, and respective isolate responses are compared with the sequences of cytochrome $b$ as the target site of QoIs. A preliminary account of this study has been presented recently (30).

\section{MATERIALS AND METHODS}

Materials and fungal cultures. Azoxystrobin (technical) and trifloxystrobin (technical) were provided by their respective manufacturers. Salicylhydroxamic acid (SHAM) was purchased from Aldrich Co. (Milwaukee, WI). Potato dextrose broth (PDB) and potato dextrose agar (PDA) was from Difco Laboratories (Pittsburgh). Disposable petri dishes were from Fisher Scientific (Pittsburgh). All other chemicals and biochemicals were purchased from Sigma-Aldrich (St. Louis), if not stated otherwise.

With the exception of isolate 98-155, $C$. graminicola isolates were collected from either annual bluegrass or creeping bent grass (Agrostis palustris L.) in Japan and the United States (Table 1). Isolate 98-155 was collected in 1998 from the ornamental nonhost Soleirolia soleirolii (Req.) Dandy 
(Irish moss, Baby's tears) grown in a private garden in California. Isolates K-3625 and K-3626 were collected from creeping bent grass in 1995 and 1996, respectively, at golf courses located in different regions of Japan. Isolate 99-78 originated from annual bluegrass in Pennsylvania in 1999. All four isolates were representatives of $C$. graminicola populations never treated with a QoI fungicide (Table 1).

Isolates K3627 and K3628 originated from diseased bent grass that had been treated in 1999 with azoxystrobin at two different golf courses in Japan serving as experimental sites for the commercial development of the fungicide. Isolates 97-72, 97-73, and 97-74 were collected in 1997 from annual bluegrass showing symptoms of anthracnose at a private golf course in Delaware where azoxystrobin had been tested for anthracnose control for three seasons. The sites exposed to azoxystrobin prior to the collection of $C$. graminicola isolates had received a total of 10 to 15 azoxystrobin treatments.

All isolates were derived from a single conidium. They were identified as $C$. graminicola according to conidia morphology and the appearance of anthracnose symptoms on infected turf grasses $(7,9)$. The isolates were preserved in a nonmetabolizing state on cellulose filter paper and were stored in vials at $4{ }^{\circ} \mathrm{C}$.

Sensitivity tests in vivo. Annual bluegrass (Valley Seed Services, Fresno, CA) and creeping bent grass (cv. Penncross) were grown in plastic pots $(10$ by $10 \mathrm{~cm})$ containing loamy-sandy soil. Absorbent clay was used to anchor seed and to provide moisture for seed germination. Pots were seeded and then watered 2 to 3 times per day using a fog nozzle. During the pregermination phase, pots were covered with paper to reduce evaporation. Grasses were grown for 2 to 3 weeks in a greenhouse ( 27 to $32^{\circ} \mathrm{C}, 14-\mathrm{h}$ photoperiod) and were cut twice to a height of 1.5 to $2 \mathrm{~cm}$ with a handheld clipper.

For tests assessing the performance of azoxystrobin, grasses were sprayed with azoxystrobin (Heritage 50WG) to evenly cover leaves, using a spray-paint gun. The spray coverage and fungicide concentration used ( $1 \mathrm{~g}$ of Heritage 50WG per liter of water) reflected the dose recommended for the control of anthracnose on turf. Grasses were inoculated $24 \mathrm{~h}$ after the fungicide was applied by misting leaves with a conidial suspension of $C$. graminicola $(2 \times$ $10^{5}$ conidia $\mathrm{ml}^{-1}$ ). Conidia were produced by growing mycelial cultures on PDA (10 $\mathrm{g}$ of PDA $+10 \mathrm{~g}$ of agar/liter) at $20^{\circ} \mathrm{C}$ and with 12-h fluorescent light photoperiods. After 7 to 10 days of incubation, conidia were harvested by gently rubbing the flooded culture surfaces (10 $\mathrm{ml}$ of water) with a glass rod and filtering conidial suspensions through two layers of cheesecloth.

The inoculated turf grasses were transferred to a dark dew chamber for $24 \mathrm{~h}$ $\left(28^{\circ} \mathrm{C}\right)$. The plants were moved into a greenhouse $\left(27^{\circ} \mathrm{C}\right.$, day and $24^{\circ} \mathrm{C}$, night with 12- to 14-h photoperiods) and the potting medium was kept moist by placing pots on wet capillary matting. Foliar anthracnose symptoms developed 10 to 14 days after inoculation. Disease severity was assessed visually and recorded as percentage of foliar tissue showing anthracnose symptoms for an entire pot. Mean disease severity values were determined in three independent experiments with three replicates each, and data from the three experiments were combined and analyzed.

Sensitivity tests in vitro. Sensitivities of C. graminicola isolates to azoxystrobin and trifloxystrobin were determined for the stage of colony growth. The fungicides were dissolved in acetone, and PDA was amended to final concentrations of 0.001 , $0.003,0.01,0.03,0.1,0.3,1,3$, and $10 \mu \mathrm{g}$ $\mathrm{ml}^{-1}$. For sensitivity tests in the presence of SHAM as an inhibitor of alternative respiration, SHAM was dissolved in methanol:acetone (1:1 [vol/vol]) and PDA was amended to a final concentration of $100 \mu \mathrm{g}$ $\mathrm{ml}^{-1}$, including control plates not amended with a QoI. This dose of SHAM provided full synergism of QoI action for QoI- sensitive isolates. Inhibition of mycelial growth with SHAM alone never exceeded $30 \%$. The final solvent concentrations of $0.1 \%$ had no effect on mycelial growth.

Agar plugs ( 2 by $2 \mathrm{~mm}$ ) containing actively growing mycelium of 4-day-old cultures of $C$. graminicola were placed on respective PDA surfaces. The diameters of colonies were measured after six days of incubation at $20^{\circ} \mathrm{C}$. Inhibitor doses required for $50 \%$ inhibition of mycelial growth $\left(\mathrm{ED}_{50}\right.$ values) were determined by regressing mean relative growth (colony diameters on QoI-amended medium/ diameters on nonamended media $\times 100$ ) against the $\log$ of QoI concentrations. Sensitivity tests were repeated three times, with three replicate colonies measured each time. All data were combined for analysis.

Characterization of cytochrome $b$ sequences. In order to determine the partial sequence of the cytochrome $b$ gene, suitable polymerase chain reaction (PCR) primers were designed by sequencing parts of the gene of isolate 99-78. Basic procedures used were as described previously $(3,17)$. Mycelium was grown in PDB for 5 days under shaking $(220 \mathrm{rpm})$ at $20^{\circ} \mathrm{C}$, harvested by filtration through miracloth, and washed with water. Mycelial pads were ground with mortar and pestle in liquid nitrogen, and DNA was extracted using the cetyltrimethylammonium bromide-based method (12). Degenerate primers were designed according to highly conserved regions of cytochrome $b$ genes. The primer pair 5'-AA(TC)GC(TAC)AC(AT)TTAAA(CT)AGA-3' and 5'-GG(AT)AT(TA)(CG)(TA)(CT)CTTA(GA)(TA)AT(TA)GC-3' amplified a 344-bp fragment in the vicinity of the C-terminus of cytochrome $b$, and the respective sequence allowed to design the homologous primer $5^{\prime}$ CATTCTGGAACTATAGCAGC-3' (P1).

In order to design a suitable PCR primer close to the N-terminus of cytochrome $b$, RNA was extracted from mycelium utilizing the Tri Reagent-RNA/DNA/Protein isolation system (Molecular Research Cen-

Table 1. Pathogenicity and in vivo sensitivities of Colletotrichum graminicola isolates to azoxystrobin

\begin{tabular}{|c|c|c|c|c|c|c|c|c|c|}
\hline \multirow[b]{2}{*}{ Isolate } & \multicolumn{3}{|c|}{ Origin } & \multicolumn{2}{|c|}{ Host specificity $^{\mathrm{a}}$} & \multicolumn{3}{|c|}{ Disease severity $^{b}$} & \multirow[b]{2}{*}{ Control $(\%)^{\mathrm{e}}$} \\
\hline & Country & Host & Exposure $^{c}$ & Bent grass & Bluegrass & Control & Treated & $P^{d}$ & \\
\hline K-3627 & Japan & Bent grass & + & + & - & $69(15)$ & $62(6)$ & 0.34 & 10.2 \\
\hline K-3628 & Japan & Bent grass & + & + & - & $79(6)$ & 77 (4) & 0.58 & 2.5 \\
\hline $97-72$ & United States & Bluegrass & + & - & + & $78(7)$ & $80(7)$ & 0.65 & 0 \\
\hline $97-73$ & United States & Bluegrass & + & - & + & $89(1)$ & $89(4)$ & 0.78 & 0 \\
\hline $97-74$ & United States & Bluegrass & + & - & + & $85(4)$ & $85(3)$ & 0.80 & 0 \\
\hline K-3625 & Japan & Bent grass & - & + & - & $44(3)$ & 0.3 & $<0.001$ & 99.3 \\
\hline K-3626 & Japan & Bent grass & - & + & - & $40(8)$ & 0.1 & 0.002 & 99.7 \\
\hline $98-155$ & United States & Irish moss & - & - & + & $45(9)$ & $7(4)$ & 0.001 & 84.4 \\
\hline $99-78$ & United States & Bluegrass & - & - & + & $65(11)$ & $1(1)$ & 0.001 & 98.5 \\
\hline
\end{tabular}

a Symptoms of foliar anthracnose were produced (+) or not produced (-) on the respective hosts.

${ }^{b}$ Disease severity is expressed as percentage of foliar tissue exhibiting anthracnose symptoms. Mean values of disease severity with standard deviations given in parentheses.

${ }^{c}$ Exposure of turf grasses was a total of 10 to 15 applications of azoxystrobin (+) or no applications (-).

$\mathrm{d}$ Probability levels for comparisons of means between grasses showing anthracnose symptoms and treated or not treated with azoxystrobin ( $t$ test).

e Percentages of control are given as 100 - relative disease severity (= mean severity of treated grasses/mean severity of nontreated grasses $\times 100)$. 
ter, Inc., Moonachie, NJ). Primer P1 was used in combination with the degenerate primer 5'-GA(GA)CA(TC)AT(TAC)ATG(AC)G(AT)GA(TC)GT-3' to amplify a 626-bp reverse transcriptase (RT)-PCR product. The second homologous primer, 5'-CATAGTAACAGCTTCTGC-3' (P2), was derived from the sequence of this fragment. The pair of homologous primers P1 and P2 allowed us to amplify RT-PCR products from all nine isolates of $C$. graminicola. The 192 amino acids of cytochrome $b$ (GenBank accession no. AY285743) corresponded to positions 82273 of the S. cerevisiae protein.

RT-PCR products were prepared for all isolates and sequenced in both directions with an ABI automated DNA sequencer with fluorescent-dye-labeled didoxy terminators at the Cornell DNA Service facility. Sequence comparisons were done using the Lasergene software (DNASTAR, Inc., Madison, WI) and the BLAST algorithm (2) provided by the National Center for Biotechnology Information.

\section{RESULTS}

Pathogenicity and in vivo sensitivities to azoxystrobin. With the exception of isolate 98-155, all isolates of C. graminicola were collected from either creeping bent grass or annual bluegrass in Japan and the United States (Table 1). All isolates were only pathogenic on the grass they had been isolated from (Table 1) and, thus, exhibited the host specificity described previously $(7,9,20)$. Isolate $98-155$ collected from Irish moss caused anthracnose on annual bluegrass but not on creeping bent grass (Table 1).

The effectiveness of azoxystrobin in preventing anthracnose development was strictly dependent on the history of azoxystrobin use prior to sampling. For all five isolates retrieved from turf treated repeatedly with azoxystrobin, anthracnose control achieved with azoxystrobin at a dose reflecting the recommended application rate was insignificant (Table 1). In contrast, all four isolates collected prior to QoI treatments were effectively controlled at the same dose (Table 1). Anthracnose caused by these four isolates was not con- trolled when azoxystrobin was applied at the same dose $24 \mathrm{~h}$ after inoculation (data not shown), indicating poor after-infection activity of the fungicide under the test conditions employed. There was no indication of decreased virulence of isolates resisting a high dose of azoxystrobin under in vivo test conditions (Table 1).

Sensitivities tests in vitro. The apparent azoxystrobin resistance of the isolates collected subsequent to repeated applications of the fungicide (Table 1) was fully confirmed in in vitro tests. Mycelia of all isolates resisting azoxystrobin in vivo displayed $\mathrm{ED}_{50}$ values of $>10 \mu \mathrm{g} \mathrm{ml}^{-1}$ in the absence and presence of SHAM employed as an inhibitor of alternative respiration (Table 2). At the highest dose of $10 \mu \mathrm{g} \mathrm{ml}^{-1}$, only one of the resistant isolates (K-3627) was significantly more sensitive to azoxystrobin when SHAM was present. However, a high level of azoxystrobin resistance was retained (Table 2). The same high level of azoxystrobin resistance was expressed during the stage of conidia germination in the presence of flavone known to inhibit the induction of alternative respiration (34; data not shown). The results indicated that the mechanism responsible for a high level of azoxystrobin resistance was unrelated to alternative respiration.

Responses to SHAM were more diverse among the four isolates of $C$. graminicola displaying a sensitive phenotype in the presence of a host than those displaying a resistant phenotype (Tables 1 and 2). For isolates K-3625 and K3626, SHAM had small yet insignificant synergistic effects on the activity of azoxystrobin (Table 2), indicating that alternative respiration was largely ineffective in the rescue of cells from QoI action. However, effects of SHAM were more pronounced for isolate 99-78, in particular at the highest dose of azoxystrobin tested (Table 2). These differences under in vitro test conditions with mycelia were not expressed in preinoculation tests in vivo, where all four isolates were equally sensitive to azoxystrobin (Table 1).

In contrast, SHAM failed to synergize azoxystrobin action for isolate 98-155 (Table 2). Therefore, this different re- sponse to SHAM was evaluated in greater detail. In the absence of SHAM, the dose responses of isolates 99-78 and 98-155 were very similar (Fig. 1). In the presence of SHAM, synergistic effects of SHAM on the sensitivity of isolate 99-78 became progressively more pronounced as the dose of azoxystobin increased, whereas SHAM had no effect on the dose response of isolate 98-155 (Fig. 1). This difference between isolates 99-78 and 98-155 was reflected in a slight yet significant $(P=0.05)$ decrease in efficacy of disease control (Table 1). Respective dose responses were different for the azoxystrobin-resistant isolate 97-72. Here, slight inhibition of mycelium by azoxystrobin was observed only at the highest dose of $10 \mu \mathrm{g} \mathrm{m} l^{-1}$, in both the absence and presence of SHAM (Fig. 1).

The various patterns of in vitro sensitivities to azoxystrobin were largely the same for trifloxystrobin. Isolate $99-78$ responded as sensitive, with synergistic action of SHAM expressed at increasingly higher

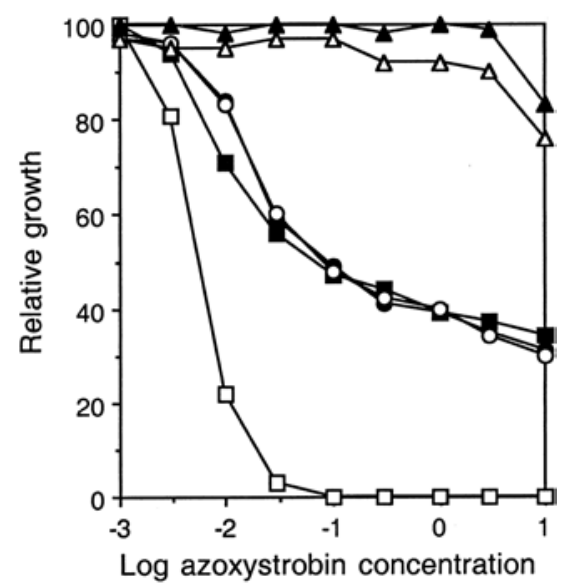

Fig. 1. Dose responses of representative Colletotrichum graminicola isolates to azoxystrobin. Sensitivities were tested in the absence (closed symbols) or presence (open symbols) of salicylhydroxamic acid at $100 \mu \mathrm{g} \mathrm{m} \mathrm{m}^{-1}$. Isolates tested were 97-72 (triangles), 98-155 (circles), and $99-78$ (squares). Relative growth is expressed as percentage of inhibition of mycelial growth -100 . Azoxystrobin concentrations are given as $\mu \mathrm{g} \mathrm{ml}^{-1}$.

Table 2. In vitro sensitivities of Colletotrichum graminicola isolates to azoxystrobin ${ }^{\mathrm{a}}$

\begin{tabular}{|c|c|c|c|c|c|c|}
\hline \multirow[b]{2}{*}{ Isolate } & \multicolumn{3}{|c|}{$\mathrm{ED}_{50}\left(\mu \mathrm{g} \mathrm{ml}^{-1}\right)$} & \multicolumn{3}{|c|}{ Inhibition $(\%)$ at $10 \mu \mathrm{g} \mathrm{ml}^{-1}$} \\
\hline & -SHAM & +SHAM & $P^{\mathbf{b}}$ & -SHAM & +SHAM & $P^{b}$ \\
\hline K-3627 & $>10$ & $>10$ & $\ldots$ & $4(5)$ & $28(8)$ & 0.03 \\
\hline K-3628 & $>10$ & $>10$ & $\ldots$ & $24(6)$ & $32(10)$ & 0.42 \\
\hline $97-72$ & $>10$ & $>10$ & $\ldots$ & $17(5)$ & $24(7)$ & 0.24 \\
\hline $97-73$ & $>10$ & $>10$ & $\ldots$ & $17(10)$ & $21(9)$ & 0.50 \\
\hline $97-74$ & $>10$ & $>10$ & & $10(10)$ & $11(8)$ & 0.95 \\
\hline K-3625 & $0.05(0.03)$ & $0.02(0.01)$ & 0.16 & 95 (4) & $100(0)$ & 0.19 \\
\hline K-3626 & $0.08(0.04)$ & $0.04(0.04)$ & 0.49 & $82(15)$ & $100(0)$ & 0.17 \\
\hline $98-155$ & $0.12(0.02)$ & $0.12(0.04)$ & 0.96 & $69(2)$ & $70(4)$ & 0.79 \\
\hline $99-78$ & $0.06(0.05)$ & $0.01(0.002)$ & 0.07 & $66(11)$ & $100(0)$ & 0.03 \\
\hline
\end{tabular}

${ }^{a}$ Mean inhibitor doses required for $50 \%$ inhibition of mycelial growth $\left(\mathrm{ED}_{50}\right.$ values) and percentages of inhibition of mycelia tested in the absence (-) and presence $(+)$ of salicylhydroxamic acid (SHAM). Standard deviations are in parenthesis.

${ }^{\mathrm{b}}$ Probability levels $\left(t\right.$ test) for comparisons of mean $\mathrm{ED}_{50}$ values and percentages of inhibition determined in the presence and absence of SHAM. 
concentrations of trifloxystrobin (Fig. 2). Isolate $98-155$ was inhibited by trifloxystrobin but, very similarly to azoxystrobin, QoI action was not influenced by SHAM (Fig. 2). Isolate 97-72, as a representative azoxystrobin-resistant isolate, was inhibited at trifloxystrobin concentrations $>1 \mu \mathrm{g} \mathrm{ml}^{-1}$, with an $\mathrm{ED}_{50}$ value of $4.9 \mu \mathrm{g} \mathrm{ml}^{-1}$ determined in the presence of SHAM (Fig. 2). In comparison to the fully sensitive isolate $99-78$ displaying an $\mathrm{ED}_{50}$ value of $0.02 \mu \mathrm{g} \mathrm{ml}^{-1}$ in the presence of SHAM (Fig. 2), the resistance factor for isolate 97-72 was 245 for trifloxystrobin and >1,000 for azoxystrobin. Although the resistance factor was smaller for trifloxystrobin, the results demonstrated full cross-resistance for the two QoIs tested.

Amino acid and nucleotide sequences of cytochrome $\boldsymbol{b}$. PCR products reflecting amino acids 82 to 273 and spanning the functional core of cytochrome $b$ were sequenced for all isolates of $C$. graminicola. The deduced amino acids were highly conserved, with only 11 amino acid exchanges $(5.7 \%)$ detected among all nine isolates (Fig. 3). The high degree of amino acid homology was reflected by the nucleotide sequences ( $92 \%$ identity) and confirmed the classification of all isolates as $C$. graminicola.

Regardless of their origin, from either Japan or the United States, and their different host specificities (Table 1), all five QoI-resistant isolates exhibited identical amino acid (Fig. 3) and nucleotide sequences (data not shown). Sequences of the sensitive isolates $\mathrm{K} 3625$ and $\mathrm{K} 3626$ collected in Japan also were identical, but they differed from QoI-resistant isolates in six amino acid positions (Fig. 3). Foremost

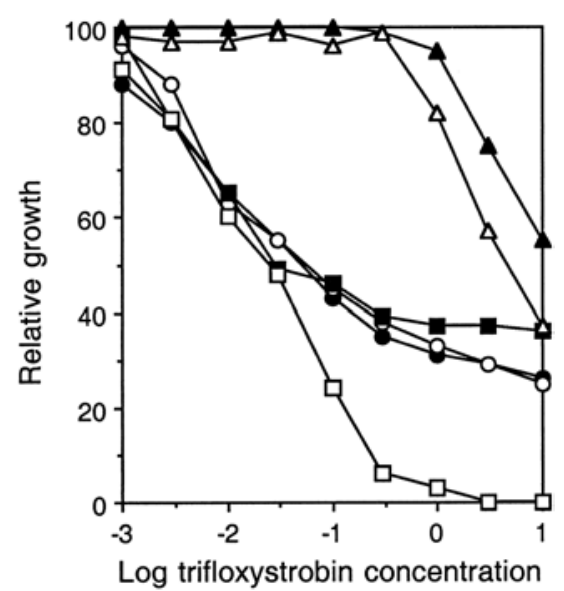

Fig. 2. Dose responses of representative Colletotrichum graminicola isolates to trifloxystrobin. Sensitivities were tested in the absence (closed symbols) or presence (open symbols) of $100 \mu \mathrm{g} \mathrm{ml}^{-1}$ SHAM. Isolates tested were 97-72 (triangles), 98-155 (circles), and 99-78 (squares). Relative growth is expressed as percentage of inhibition of mycelial growth - 100. Trifloxystrobin concentrations are given as $\mu \mathrm{g} \mathrm{ml} \mathrm{m}^{-1}$. was the G143A exchange affiliated with several other pathogens developing practical resistance to QoIs $(8,18,19)$. In addition, the two sensitive isolates from Japan were distinguished from resistant isolates by three leucine-to-threonine exchanges in positions 95, 130, and 141, a cysteine-tothreonine exchange in position 118, and an isoleucine-to-methionine exchange in position 232 (Fig. 3).

As expected, the sensitive isolates 98155 and 99-78 had retained a glycine in position 143 (Fig. 3). However, only isolate 98-155 shared the three leucines in positions 95, 130, and 141 with the two sensitive isolates collected in Japan, whereas isolate 99-78 displayed all three leucine-to-threonine exchanges found in the homologous group of azoxystrobinresistant isolates (Fig. 3). A similar pattern applied to the isoleucine-tomethionine exchange in position 232; however, here, the exchange pattern was reversed for the two sensitive U.S. isolates (Fig. 3). Other amino acid permutations were detected in positions 132, 199, 227 , and 243 , but they were restricted to the QoI-sensitive isolates collected in the United States (Fig 3).

Eight amino acid exchanges detected in cytochrome $b$ of the $C$. graminicola isolates were based on single nucleotide transversions, whereas three exchanges, including the leucine-to-threonine exchange in position 130 , were based on two nucleotide transversions (Table 3). The nucleotide most prominently involved in transversions was thymine, with T-to-A and T-to-C transversions observed most frequently (Table 4). For transversions involving guanine, the G-to-C transversions responsible for G143A exchanges were most prominent (Table 4). Predominance of thymine transversions reflected the high thymine content of the sequenced cytochrome $b$ portion (Table 4). Although transversions involving thymine and guanine were slightly higher or lower than reflected by the overall nucleotide usage (Table 4), this difference was not significant $(P=0.18)$. The results indicated that all four nucleotides had been subjected to transversions at a frequency reflecting their overall usage.

\begin{tabular}{|c|c|c|c|c|c|}
\hline \multirow[b]{2}{*}{ G143A } & \multirow[b]{2}{*}{ (res) } & \multicolumn{2}{|r|}{90} & \multirow{2}{*}{$\begin{array}{l}100 \\
\text { GMYYGSYRAP }\end{array}$} & \multirow{2}{*}{110} \\
\hline & & HSNTASAF & FFLVYTHVGR & & \\
\hline K3625 & (sen) & HSNTASAF & FFLVYLHVGR & GMYYGSYRAP & RTLVWVMGCM \\
\hline K3626 & (sen) & HSNTASAF & FFLVYLHVGR & GMYYGSYRAP & RTLVWVMGCM \\
\hline $98-155$ & (sen) & HSNTASAF & FFLVYLHVGR & GMYYGSYRAP & RTLVWVMGAM \\
\hline $99-78$ & (sen) & HSNTASAF & FELVYTHVGR & GMYYGSYRAP & RTLVWVMGTM \\
\hline & & 120 & 130 & 140 & 150 \\
\hline G143A & (res) & MTVAMMGMGF & TGYVLPYGQM & STWAATVITN & TMSAIPWIG \\
\hline K3625 & (sen) & MTVAMMGMGF & LGYVLPYGQM & SLWGATVITN & TMSAIPWIG \\
\hline K3626 & (sen) & MTVAMMGMGF & LGYVLPYGQM & SLWGATVITN & TMSAIPWIGQ \\
\hline $98-155$ & (sen) & MTVAMMGMGF & LGYVLPYGQM & SLWGATVITN & TMSAIPWIG \\
\hline $99-78$ & (sen) & MTVAMMGMGF & TGHVLPYGQM & STWGATVITN & TMSAIPWIG \\
\hline & & 160 & 170 & 180 & 190 \\
\hline G143A & (res) & DIVEFVWGGF & SVNNATLNRF & FALHFVLPFV & LAALVLMHI \\
\hline K3625 & (sen) & DIVEFVWGGF & SVNNATLNRF & FALHFVLPFV & LAALVLMH \\
\hline K3626 & (sen) & DIVEFVWGGF & SVNNATLNRF & FALHFVLPFV & LAALVLMH. \\
\hline $98-155$ & (sen) & DIVEFVWGGF & SVNNATLNRE & FALHFVLPFV & LAALVLMH. \\
\hline $99-78$ & (sen) & DIVEFVWGGF & SVNNATLNRF & FALHFVLPFV & LAALVLMH \\
\hline & & 200 & 210 & 220 & 230 \\
\hline G143A & (res) & ATHDTVGSSN & PLGVSGNYDR & MPFAPYYLFK & DLMTMFMF \\
\hline K3625 & (sen) & ATHDTVGSSN & PLGVSGNYDR & MPFAPYYLFK & DLITMFMF \\
\hline K3626 & (sen) & ATHDTVGSSN & PLGVSGNYDR & MPFAPYYLFK & DLITMFMFVF \\
\hline $98-155$ & (sen) & ATHDTVGSSN & PLGVSGNYDR & MPFAPYYTFK & DLMTMFMFVF \\
\hline $99-78$ & (sen) & ATHDTVGSSN & PLGVSGNYDR & MPFAPYYLFK & DLITMFMFT \\
\hline & & 240 & 250 & 260 & 270 \\
\hline G143A & (res) & GLSLFVFFMP & NVLGDSDNYM & MANPMQTPAA & MVPE \\
\hline K3625 & ( $s$ & GLSLFVFFMP & NVLGDSDNYM & MANPMQTPAA & MVPE \\
\hline K3626 & (sen) & GLSLFVFFMP & NVLGDSDNYM & MANPMQTPAA & MVPE \\
\hline $98-155$ & (sen) & GLSTFVFFMP & NVLGDSDNYM & MANPMQTPAA & MVPE \\
\hline $99-78$ & (sen) & GLSLFVFFMP & NVLGDSDNYM & MANPMQTPAA & MVPE \\
\hline
\end{tabular}

Fig. 3. Amino acid sequences of cytochrome $b$ segments expressed by isolates of Colletotrichum graminicola responding resistant (res) or sensitive (sens) to azoxystrobin. The sequences of all resistant isolates (K3627, K3628, 97-72, 97-73, and 97-74) were fully homologous and are combined as G143A. The amino acids exchanged are presented in bold. 


\section{DISCUSSION}

For several plant pathogens, the selection of QoI-resistant subpopulations has progressed more rapidly than anticipated, and a G143A mutation of the cytochrome $b$ target site was identified as the cause of resistance in the majority of reported cases $(8,15,18,19,21,39,40,42)$. The results described here indicate that $C$. graminicola belongs to the group of pathogens prone to rapid resistance development. Highly resistant G143A target site mutants were selected in Japan and the United States in response to the treatment of turf with a total of 10 to 15 azoxystrobin applications at each location. The unimpaired virulence of respective mutants had, most likely, contributed to their rapid selection.

The cytochrome $b$ sequences of all five QoI-resistant isolates of $C$. graminicola described here were fully homologous, regardless of their origin and their different host specificities. In addition to the G143A amino acid exchange, the QoI-resistant isolates were distinguished by amino acid exchanges in other positions. The most consistent difference identified for three of the four sensitive isolates was a leucine-tothreonine exchange in positions 95, 130, and 141. An arbitrary nature of these three additional amino acid permutations is unlikely, in particular because the L130T exchange was based on two nucleotide transversions.

The results indicate that amino acid exchanges in addition to the resistanceconferring G143A mutation might have been involved in the occasionally rapid selection of fully competitive QoI-resistant subpopulations. Although speculative at present, such additional amino acid exchanges might compensate for functional impairments caused by cytochrome $b$ mutations toward decreased QoI binding af-

Table 3. Amino acid and nucleotide polymorphism in cytochrome $b$ genes of nine Colletotrichum graminicola isolates

\begin{tabular}{|c|c|c|}
\hline Position $^{\text {a }}$ & Amino acid ${ }^{b}$ & Codon $^{c}$ \\
\hline 95 & $\mathrm{~L} / \mathrm{T}$ & TTA/CTA \\
\hline 118 & $\mathrm{C} / \mathrm{T}$ & TGT/ACT \\
\hline 118 & $\mathrm{C} / \mathrm{A}$ & TGT/GCT \\
\hline 130 & $\mathrm{~L} / \mathrm{T}$ & TTA/CTG \\
\hline 132 & $\mathrm{Y} / \mathrm{H}$ & TAT/CAT \\
\hline 141 & $\mathrm{~L} / \mathrm{T}$ & TTA/CTA \\
\hline 143 & G/A & GGT/GCT \\
\hline 199 & $\mathrm{M} / \mathrm{I}$ & ATA/ATC \\
\hline 227 & $\mathrm{~L} / \mathrm{T}$ & TTA/CTA \\
\hline 232 & $\mathrm{I} / \mathrm{M}$ & ATA/ATC \\
\hline 243 & $\mathrm{~L} / \mathrm{T}$ & TTA/CTA \\
\hline
\end{tabular}

a Amino acid positions of cytochrome $b$ deduced from nucleotide sequences.

${ }^{\mathrm{b}}$ Amino acid exchanges relative to the amino acids expressed by the QoI-sensitive reference isolate K3625. Amino acids of the reference isolate are given first, followed by the amino acids identified in eight other isolates at respective positions.

${ }^{c}$ Nucleotides encoding the amino acids in reference isolate $\mathrm{K} 3625$ and respective amino acids exchanged in the other isolates. finities. A functional impairment of mutated cytochrome $b$ has been reported for several point mutations conferring QoI resistance to $S$. cerevisea $(11,26)$. Additional amino acid exchanges existing prior to G143A mutations might enable mutated mitochondria to retain full respiratory functionality, facilitating their selection to a homoplasmic stage. If this hypothesis is correct, one of the three QoI-sensitive isolates of $C$. graminicola described here would already carry the three leucine-tothreonine exchanges found in all QoIresistant G143A mutants, and a single mutation in the 143 position of cytochrome $b$ would be sufficient to render QoI resistance without compromising competitiveness of resistant mutants.

The three leucines in positions 95, 130, and 141 under discussion are highly conserved in the cytochrome $b$ of other fungal pathogens $(39,45)$. Although analyses of sequence data surrounding the G143A mutation site of cytochrome $b$ remain scarce and restricted to a small numbers of isolates, diversions from the highly conserved leucines in respective positions have been described for other G143A target site mutants. For example, the leucines in positions 130 and 141 were conserved in a QoI-sensitive isolate of Podosphaera fusca (syn: Sphaerotheca fuliginea), but both were exchanged in the two QoI-resistant G143A mutants described (21). Amino acids in the same positions departed from the normally conserved leucine in the cytochrome $b$ of two sensitive but also three QoI-resistant isolates of Pseudoperonospora cubensis (21). For Erysiphe graminis f. sp. tritici, leucine in position 141 was exchanged to a histidine in both a sensitive and a G143A mutant (40). Interestingly, the selection of fully competitive QoIresistant isolates was rapid for all three pathogens $(10,21,40)$. Our finding that one of four QoI-sensitive isolates of $C$. graminicola already contained all three leucine-to-threonine exchanges consis- tently found in the G143A-resistant isolates might have contributed to the rapid selection of fully competitive QoI-resistant mutants.

A second, not yet fully understood question concerns the origin of G143A mutations conferring QoI target site resistance. In contrast to previous targets of fungicide action, the gene encoding the cytochrome $b$ target of QoIs is of mitochondrial origin and, thus, is represented by multiple alleles. Mutational changes of mitochondrial genes are facilitated by a relatively high mutation rate of mitochondrial DNA $(25,38)$. One of the major causes of such accelerated mutations is the oxidative damage of nucleotides by reactive oxygen species generated during mitochondrial respiration $(25,38)$, with guanine and thymine known to be most prone to oxidation (13). If not repaired, oxidative damage of nucleotides can lead to mismatches during DNA replication and, thus, to potentially permanent nucleotide transversions in mitochondrial genes $(25,38)$. In all cases reported thus far and including the resistant $C$. graminicola mutants described here, the G143A exchanges were caused by a single guanine-to-cytosine transversion.

Oxidative damage of guanine responsible for mutational nucleotide mismatches is known to generate 8-hydroxyguanine, which mispairs with adenine during DNA replication, leading to the replacement of guanine by thymine $(13,41)$. Such guanine transversions were not apparent in the cytochrome $b$ sequences described in this study. However, products originating from a second oxidation of 8-hydroxyguanine have been reported to mispair with guanine (28) and, thus, would account for the guanine-to-cytosine transversions identified for all G143A target site mutants resisting high levels of QoIs. In addition to guanine, thymine also is prone to oxidative damage. Oxidation of the methyl group in thymine generates 5-formyluracil, a nucleotide reported to potentially mispair with guanine,

Table 4. Nucleotide usage and nucleotide transversions in the cytochrome $b$ alleles of nine Colletotrichum graminicola isolates

\begin{tabular}{|c|c|c|c|c|}
\hline \multirow[b]{2}{*}{ Nucleotides } & \multicolumn{2}{|c|}{ Nucleotide usage $^{a}$} & \multicolumn{2}{|c|}{ Transversions $^{\mathrm{b}}$} \\
\hline & $n$ & $\%$ & $n$ & $\%$ \\
\hline Thymine & 228 & 39.6 & 24 & 50.0 \\
\hline $\mathrm{T}: \mathrm{A}$ & $\ldots$ & $\ldots$ & 13 & $\ldots$ \\
\hline $\mathrm{T}: \mathrm{C}$ & $\ldots$ & $\ldots$ & 10 & $\ldots$ \\
\hline $\mathrm{T}: \mathrm{G}$ & $\ldots$ & $\ldots$ & 1 & $\ldots$ \\
\hline Adenine & 157 & 27.3 & 10 & 20.8 \\
\hline$A: G$ & $\ldots$ & $\ldots$ & 5 & $\ldots$ \\
\hline $\mathrm{A}: \mathrm{C}$ & $\ldots$ & $\ldots$ & 3 & $\ldots$ \\
\hline A:T & . & & 2 & $\ldots$ \\
\hline Cytosine & 90 & 15.6 & 10 & 20.8 \\
\hline $\mathrm{C}: \mathrm{T}$ & $\ldots$ & $\ldots$ & 9 & $\ldots$ \\
\hline $\mathrm{C}: \mathrm{G}$ & $\ldots$ & $\ldots$ & 1 & $\ldots$ \\
\hline Guanine & 101 & 17.5 & 4 & 8.4 \\
\hline $\mathrm{G}: \mathrm{C}$ & $\ldots$ & $\ldots$ & 3 & $\ldots$ \\
\hline G:A & $\ldots$ & $\ldots$ & 1 & $\ldots$ \\
\hline
\end{tabular}

${ }^{a}$ Nucleotides used in the sequenced part of the cytochrome $b$ allele expressed by the QoI-sensitive reference isolate $\mathrm{K} 3625$.

b Nucleotide transversions identified in the partial cytochrome $b$ genes of eight other isolates. 
thymine, or cytosine $(24,29)$. The various point mutations generated by such mismatches would account for all nucleotide transversions of thymine described here for cytochrome $b$ of $C$. graminicola and for most of the several leucine-to-threonine exchanges in cytochrome $b$.

Inhibition of electron transport at the level of cytochrome $b$ is known to increase the concentration of reactive oxygen species in mitochondria $(23,26)$ and, thus, can be expected to transiently increase the oxidative damage of nucleotides responsible for mutagenic mismatches during DNA replication. Whether accelerated mutagenesis of mitochondrial DNA under the action of a QoI is involved in the generation of target-site-resistant cytochrome $b$ alleles remains unknown at present, but it cannot be excluded. For example, the spontaneous emergence of two distinct target site mutants both based on the transversion of guanine has been reported recently for $M$. grisea subjected to azoxystrobin-mediated oxidative stress $(4,6)$. An accelerated adaptation of fungicide-resistant populations to new fungicides in general has been described for $V$. inaequalis (27).

The results described here for $C$. graminicola have impact on the management of azoxystrobin resistance in the control of anthracnose. Our comparison of azoxystrobin with trifloxystrobin revealed that cross-resistance exists among the class of QoI fungicides. Similar to other pathogens (36), the highly resistant isolates of $C$. graminicola described here had reached an apparent homoplasmic stage and were not impaired in their competitive fitness. Once such resistant isolates reach a high frequency in response to treatment with QoIs, the fungicides will become ineffective in the control of anthracnose. Our observation that the G143A mutation was accompanied by three additional leucine-to-threonine exchanges in cytochrome $b$ found in three of the four sensitive isolates indicates that target site mutants lacking these additional amino acid exchanges might retain a heteroplasmic cytochrome $b$ allele population for a longer period of time and might return to a more sensitive stage once they are relieved from the selection pressure. For example, some QoI-resistant isolates of $E$. graminis f. sp. tritici containing a mixed allele population for cytochrome $b$ were found to slowly return to a QoI-sensitive stage once they were relieved from the selection pressure (15). In such cases, restricting the number of QoI applications over a season of anthracnose management would compose a valuable tool in resistance management.

In summary, our data document that $C$. graminicola belongs to the group of pathogens with the potential for rapid emergence of fully competitive QoI-resistant mutants. Once such target site mutants are selected to a high frequency, QoIs will lose their effectiveness and should no longer be used in the management of anthracnose. The question of how fast this stage of ineffectiveness will be reached at particular sites will depend on several parameters, such as the QoI use history, the particular population structure of $C$. graminicola, and environmental conditions favoring rapid population growth. Guidance in these questions can be provided only by continuous monitoring programs, either with bioassays according to the sensitivity data provided in this study, or with PCR-based tests evaluating the frequency of G143A mutations within a given population of $C$. graminicola.

As reported for several pathogens $(5,32-$ 34,46 ), the variable interference of alternative respiration with QoI action had no impact on the protective performance of azoxystrobin in the control of anthracnose. This predictive limitation of bioassays based on mycelial growth must be considered in the design of respective monitoring procedures. PCR-based tests aimed at the G143A exchange conferring QoI resistance have been described recently $(15,42)$. For C. graminicola, such tests should include the additional amino acid exchanges potentially involved in predisposing sensitive isolates toward fully functional G143A mutations.

\section{LITERATURE CITED}

1. Agnew, M., Young, T., Houseworth, D., and Laird, D. 1998. Use of trifloxystrobin on turfgrass. (Abstr.) Phytopathology 88:S2.

2. Altschul, S. F., Madden, T. L., Schäffer, A. A., Zhang, J., Zhang, Z., Miller, W., and Lipman. 1997. Gapped BLAST and PSI-BLAST: A new generation of protein database search programs. Nucleic Acids Res. 25:3389-3402.

3. Avila-Adame, C., and Köller, W. 2002. Disruption of the alternative oxidase gene in Magnaporthe grisea and its impact on host infection. Mol. Plant-Microbe Interact. 15:493-500.

4. Avila-Adame, C., and Köller, W. 2002. Interrelation between alternative respiration and target site mutations in response to QoI fungicides. Pages 829-834 in: Proc. Brighton Conf. Pests Dis. 2002. British Crop Protection Council, Farnham, U.K.

5. Avila-Adame, C., and Köller, W. 2003. Impact of alternative respiration and target site mutations on responses of germinating conidia of Magnaporthe grisea to QoI-inhibiting fungicides. Pest Manage. Sci. 59:303-309.

6. Avila-Adame, C., and Köller, W. 2003. Characterization of spontaneous mutants of Magnaporthe grisea expressing stable resistance to the Qo-inhibiting fungicide azoxystrobin. Curr. Genet. 42:332-338.

7. Backman, P. A., Landschoot, P. J., and Huff, D. R. 1999. Variation in pathogenicity, morphology, and RAPD marker profiles in Colletotrichum graminicola from turfgrasses. Crop Sci. 39:1129-1135.

8. Bartlett, D. W., Clough, J. M., Godwin, J. R., Hall, A. A., Hamer, M., and Parr-Dobranzki, B. 2002. The strobilurin fungicides. Pest Manage. Sci. 58:649-662.

9. Browning, M., Rowley, L. V., Zeng, P., Chandlee, J. M., and Jackson, N. 1999. Morphological, pathogenic, and genetic comparisons of Colletotrichum graminicola isolates from Poacea. Plant Dis. 83:286-292.

10. Chin, K. M., Chavaillaz, D., Kaesbohrer, M.,
Staub, T., and Felsenstein, F. G. 2001. Characterizing resistance risk of Erysiphe graminis $\mathrm{f}$ sp. tritici to strobilurins. Crop Prot. 20:87-96.

11. Colson, A.-M. 1993. Random mutant generation and its utility in uncovering structural and functional features of cytochrome $b$ in Saccharomyces cerevisiae. J. Bioenerg. Biomembr. 25:211-220.

12. Csaikl, U. M., Bastian, H., Brettschneider, R. Gauch, S., Meir, A., Scauerte, M., Scholz, F., Sperisen, C., Vornam, B., and Ziegenhagen, B. 1998. Comparative analysis of different DNA extraction protocols: A fast, universal maxi-preparation of high quality plant DNA for genetic and phylogenetic studies. Plant Mol. Biol. Rep. 16:69-86.

13. Demple, B., and Harrison, L. 1994. Repair of oxidative damage to DNA: Enzymology and Biology. Annu. Rev. Biochem. 63:915-948.

14. Farman, M. L. 2001. The molecular basis of field resistance to QoI fungicides in Pyricularia grisea. (Abstr.) Phytopathology 91:S110.

15. Fraaije, B. A., Butters, J. A., Coelho, J. M., Jones, D. R., and Hollomon, D. W. 2002. Following the dynamics of strobilurin resistance in Blumeria graminis f. sp. tritici using quantitative allele-specific real-time PCR measurements with the fluorescent dye SYBR Green I. Plant Pathol. 51:45-54.

16. Frank, J. A., and Sanders, P. L. 1994 ICI5504: A novel, broad-spectrum, systemic turfgrass fungicide. Pages 871-876 in: Proc. Brighton Conf. Pests Dis. 1994. British Crop Protection Council, Farnham, U.K.

17. Garber, R. C., and Yoder, O. C. 1983. Isolation of filamentous fungi and separation into nuclear, mitochondrial and ribosomal and plasmid components. Anal. Biochem. 135:416-422.

18. Gisi, U., Sierotzki, H., Cook, A., and McCaffery, A. 2002. Mechanisms influencing the evolution of resistance to Qo inhibitor fungicides. Pest Manage. Sci. 58:859-867.

19. Heaney, S. P., Hall, A. A., Davies, S. A., and Olaya, G. 2000. Resistance to fungicides in the QoI-STAR cross-resistance group: Current perspectives. Pages 755-762 in: Proc. Brighton Conf. Pests Dis. 2000. British Crop Protection Council, Farnham, U.K.

20. Hsiang, T., and Goodwin, P. H. 2001. Ribosomal DNA sequence comparisons of Colletotrichum graminicola from turfgrasses and other hosts. Eur. J. Plant Pathol. 107:593-599.

21. Ishii, H., Fraaije, B. A., Sugiyama, T., Noguchi, K., Nishimura, K., Takeda, T., Amano, T., and Hollomon, D. W. 2001. Occurrence and molecular characterization of strobilurin resistance in cucumber powdery mildew and downy mildew. Phytopathology 91:11661171.

22. Jordan, D. B., Livingston, R. S., Bisaha, J. J., Duncan, K. E., Pember, S. O., Picollelli, M. A., Schwartz, R. S., Sternberg, J. A., and Tang, X. S. 1999. Mode of action of famaxadone. Pestic. Sci. 55:105-118.

23. Joseph-Horne, T., Hollomon, D. W., and Wood, P. M. 2001. Fungal respiration: A fusion of standard and alternative components. Biochim. Biophys. Acta 1504:179-195.

24. Kamiya, H., Murata-Kaliya, N., Karino, N., Ueno, Y., Matsuda, A., and Kasai, H. 2002. Induction of $\mathrm{T}$ to $\mathrm{G}$ and $\mathrm{T}$ to $\mathrm{A}$ transversions by 5 -formyluracil in mammalian cells. Mutat. Res. 513:213-222.

25. Kang, D., and Hamasaki, N. 2002. Maintenance of mitochondrial DNA integrity: repair and degradation. Curr. Genet. 41:313-322.

26. Köller, W., Avila-Adame, C., Olaya, G., and Zheng, D. 2001. Resistance to strobilurin fungicides. Pages 215-229 in: Agrochemical Resistance-Extent, Mechanism, and Detection. J. M. Clark and I. Yamaguchi, eds. American 
Chemical Society, Washington, DC.

27. Köller, W., and Wilcox, W. F. 2001. Evidence for the predisposition of fungicide-resistant isolates of Venturia inaequalis to a preferential selection for resistance to other fungicides. Phytopathology 91:776-781.

28. Leipold, M. D., Muller, J. G., Burrows, C. J., and David, S. S. 2000. Removal of hydantoin products of 8-oxoguanine oxidation by the Escherichia coli DNA repair enzyme, FPG. Biochemistry 39:14984-14992.

29. Masaoka, A. Terato, H. Kobayashi, M. Ohyama, Y., and Ide, H. 2001. Oxidation of thymine to 5-formyluracil in DNA promotes missincorporation of dGMP and subsequent elongation of a mismatched primer terminus by DNA polymerase. J. Biol. Chem. 276:16501-16510.

30. Olaya, G., Avila-Adame, C., and Köller, W. 2002. Resistance of Colletotrichum graminicola to QoI inhibitors. (Abstr.) Phytopathology 92:S61.

31. Olaya, G., Cleere, S., Stanger, C., Burbidge, J., Hall, A., and Windass, J. 2003. A novel potential target site QoI fungicide resistance mechanism in Pythium aphanidermatum. (Abstr.) Phytopathology 93:S67.

32. Olaya, G., and Köller, W. 1999. Baseline sensitivities of Venturia inaequalis populations to the strobilurin fungicide kresoximmethyl. Plant Dis. 83:274-278.

33. Olaya, G., and Köller, W. 1999. Diversity of kresoxim-methyl sensitivities in baseline populations of Venturia inaequalis. Pestic. Sci. 55:1-6.

34. Olaya, G., Zheng, D., and Köller, W. 1998. Differential responses of germinating Venturia inaequalis conidia to kresoxim-methyl. Pestic. Sci. 54:230-236.

35. Pasche, J. S., Wharsam, C. M., and Gudmestad, N. C. 2002. Shift in sensitivity of Alternaria solani (potato early blight) to strobilurin fungicides. Pages 841-846 in: Proc. Brighton Conf. Pests Dis. 2002. British Crop Protection Council, Farnham, U.K.

36. Robinson, H. L., Ridout, C. J., Sierotzki, H., Gisi, U., and Brown, J. K. M. 2002. Isogamous, hermaphroditic inheritance of mitochondrion-encoded resistance to Qo inhibitor fungicides in Blumeria graminis f. sp. tritici. Fungal. Genet. Biol. 36:98-106.

37. Sauter, H., Steglich, W., and Anke, T. 1999. Strobilurins: Evolution of a new class of active substances. Angew. Chem. Int. Ed. 38:1328-1349.

38. Sawyer, D. E., and Van Houten, B. 1999. Repair of DNA damage in mitochondria. Mutat. Res. 434:161-176.

39. Sierotzki, H., Parisi, S., Steinfeld, U., Tenzer, I., Poirey, S., and Gisi, U. 2000. Mode of resistance to respiration inhibitors at the cytochrome bc1 enzyme complex of Mycospherella fijiensis field isolates. Pest Manage. Sci. 56:833-841.

40. Sierotzki, H., Wullschleger, J., and Gisi, U. 2000. Point mutation in cytochrome $b$ gene conferring resistance to strobilurin fungicides in Erysiphe graminis f. sp. tritici field isolates. Pestic. Biochem. Physiol. 68:107-112.

41. Singh, K. K., Sigala, B., Sikder, H., and Schwimmer. Inactivation of Saccharomyces cerevisiae OGG1 DNA repair gene leads to an increased frequency of mitochondrial mutants. Nucleic Acids Res. 29:1381-1388.

42. Sirven, C., Gonzalez, E., Buffler, E., Latorse, M. P. and Beffa, R. 2002. PCR-based method for detecting mutation allele frequencies for QoI resistance in Plasmopora viticola. Pages 823-828 in: Proc. Brighton Conf. Pests Dis. 2002. British Crop Protection Council, Farnham, U.K.

43. Smiley, R. W., Dernoeden, P. H., and Clark, B. B. 1992. Compendium of Turfgrass Diseases, 2nd ed. American Chemical Society, St. Paul, MN.

44. Ypema, H. L., and Gold, R. E. 1999. Kresoxim-methyl. Modification of a natural occurring compound to produce a new fungicide. Plant Dis. 83:4-19.

45. Zheng, D., Olaya, G., and Köller, W. 2000 Characterization of laboratory mutants of Venturia inaequalis resistant to the strobilurin-related fungicide kresoxim-methyl. Curr. Genet. $38: 148-155$.

46. Ziogas, B. N., Baldwin, B. C., and Young, J. E. 1997. Alternative respiration: A biochemical mechanism of resistance to azoxystrobin (ICIA 5504) in Septoria tritici. Pestic. Sci. $50: 28-34$ 